\title{
Mapeamento das manifestações patológicas de edificação histórica de Campina Grande: A estação ferroviária como patrimônio Art Déco
}

\author{
E.M. Mendes ${ }^{1}$, M.P. Viana ${ }^{1}$, T.P. Albuquerque ${ }^{*}$, T.B. Araújo ${ }^{1}$ \\ *Autor de Contacto: tairone.albuquerque@maisunifacisa.com.br \\ 1 Departamento de Engenharia Civil, Universidade Unifacisa, Campina Grande, Brasil.
}

\begin{abstract}
RESUMO
As fachadas correspondem à identidade visual de uma edificação, sua exposição direta a intempéries desencadeia manifestações patológicas. Este artigo tem como objetivo identificar e apresentar as condições de preservação das fachadas do edifício principal destinado à Estação Ferroviária Nova, fazendo um resgate histórico do edifício e da art déco na cidade. A metodologia baseia-se em levantamento bibliográfico, inspeção visual, mapeamento de danos e aplicação da Matriz (GUT) Gravidade, Urgência, Tendência. As principais manifestações patológicas atuantes referem-se a problemas estruturais, fissuras, descascamentos, descolamentos de argamassa e danos relacionados à umidade e principalmente atreladas a ações antropológicas. $\mathrm{O}$ estado de conservação é preocupante e necessita de intervenções imediatas.
\end{abstract}

Palavras chave: Manifestações patológicas; Mapa de danos; Matriz GUT; Fachada; Art déco.

\begin{abstract}
The facades correspond to the visual identity; its exposure to bad weather triggers pathological manifestations. This article aims to identify and present the preservation of the facades of the main building destined for railway station through the damage map and the historical rescue of the building and art Déco. The methodology is based on a bibliographic survey, visual inspection, damage mapping, and application of the Matrix (GUT) Gravity, Urgency, Trend. The main pathological manifestations present refer to structural problems, cracks, peeling, mortar detachment, and damage related to humidity and mainly linked to anthropological actions. The state of conservation is worrying and needs immediate interventions.
\end{abstract}

KEYWORDS: Pathological manifestations; Damage map; GUT matrix; facade; Art Deco.

\section{INTRODUÇÃO}

O edifício principal destinado a Estação Ferroviária Nova, objeto de estudo deste artigo, foi referência para o desenvolvimento da cidade e toda a história da cultura algodoeira, sua 
infraestrutura configurou uma nova forma urbana para a cidade de Campina Grande, na Paraíba. Com características modernistas em estilo Art Déco, a edificação foi inaugurada em 1961, como comemoração aos 50 anos da chegada do trem ao município.

O transporte ferroviário utiliza a estrada de ferro, e seus veículos são os trens, trata-se de um modal sem flexibilidade, mas com alta capacidade de transporte de materiais. Santos (2019) afirma que com o impulso industrial automobilístico, este modal passou a ser visto como algo ultrapassado e a sociedade enxergava nos transportes rodoviários a agilidade e flexibilidade que o transporte ferroviário não mais oferecia. Com a concorrência desleal, os complexos ferroviários foram negligenciados e esquecidos pelos órgãos mantenedores.

Segundo Andrade et al. (2005), a edificação é um patrimônio cultural assim como a arte, uma das linhas mestras de desenvolvimento da civilização. Deste modo, representa a época em que foi construída, a técnica empregada e o contexto físico e social em que está inserida, tornando-se um testemunho dos valores sociais e do momento histórico no qual foi concebido.

Com o passar dos anos e a utilização dessas edificações, ocorre a degradação natural dos seus materiais constituintes, devido à ação das intempéries. A ausência de comprometimento dos órgãos públicos com os procedimentos de manutenção e reparos de eventuais manifestações patológicas, acarreta uma considerável redução de sua vida útil. Scheidegger (2019) alerta para necessidade de detecção precoce dos problemas patológicos como chave para que não haja um comprometimento total da estrutura, uma vez que, o quanto antes for localizado, analisado e tratado, tende a reduzir as possibilidades de condenação e os custos para uma eventual reparação.

Tais constatações auxiliam a pensar um importante equipamento cultural tombado pelo Instituto do Patrimônio Histórico e Artístico do Estado da Paraíba (IPHAEP), que atualmente encontra-se completamente abandonado e desassistido, perdendo suas características e potencializando manifestações patológicas.

Então, este artigo tem como objetivo geral identificar as manifestações patológicas e as condições de preservação das fachadas do edifício principal da Estação Nova. Para isso, apresenta como objetivos específicos: resgatar a história da estação nova e Art Déco; elaborar o mapeamento dos danos existentes.

A metodologia utilizada para a elaboração do presente estudo baseou-se nas diretrizes para representação gráfica de mapa de danos de Achiamé e Filho (2018). E nos estudos desenvolvidos por Tinoco (2009) para inspecionar fachadas de valor histórico apresentando de maneira técnica as manifestações patológicas presentes em edificações de valor cultural. Para conhecer o estado de degradação das fachadas e fornecer subsídios para tomadas de decisões, aplicamos a Matriz GUT (Gravidade, Urgência e Tendência) além da análise de levantamentos bibliográficos acerca da problemática.

Na busca de investigar tais manifestações, Santos (2018) define a função da envoltória (fachadas e cobertura) como a proteção dos espaços interiores das condições adversas do exterior, servindo como barreira para estes agentes. Por estar exposto a diversas intempéries, os casos mais comuns de manifestações patológicas identificadas em fachadas estão atrelados aos descolamentos de pastilhas, fissuração dos revestimentos, degradação de pinturas, presença de eflorescência e bolor, entre outros.

Por isso, elaborar o Mapa de Danos contribui na verificação das manifestações patológicas nas edificações, de acordo com Barthel et al. (2009, p.1):

O Mapa de Danos se aplica somente aos bens culturais materiais e consiste na representação gráfica e sintética dos danos físicos existentes no bem histórico. É resultado de pesquisas mais aprofundadas sobre o edifício que levarão ao conhecimento do estado de conservação para fundamentação da postura de intervenção a ser adotada. 
Desse modo, esse estudo resgata a importância da arquitetura Art Déco presente na edificação da Estação Ferroviária Nova que representou o avanço da urbanização na cidade. Mostrando a atual condição do espaço que outrora foi símbolo de modernidade e tecnologia.

\section{METODOLOGIA DE PESQUISA}

Esse trabalho foi dividido em etapas, com a finalidade de organizar os procedimentos necessários para a realização do mapeamento de danos das fachadas do edifício principal destinado à Estação Nova, localizado no complexo ferroviário da cidade de Campina Grande- PB. A natureza da pesquisa pode ser classificada como qualitativa e exploratória, a partir de um estudo de caso, de acordo com o tema escolhido.

A primeira etapa da elaboração consistiu na coleta de dados, foi executado um estudo bibliográfico com material especializado, como livros, monografias, cartilhas, artigos, entre outros materiais. A segunda foi a inspeção visual, com levantamento arquitetônico e documentação fotográfica das fachadas. Na terceira etapa foi feita a organização e análise dos dados coletados para posterior confecção do mapeamento de danos e aplicação da metodologia da matriz GUT, produzido em softwares especializados como AutoCAD e Excel. O produto final desta pesquisa é o mapa de danos e o gráfico de priorização das fachadas.

\section{ART DÉCO}

Munduruca (2013) contextualiza o surgimento da arquitetura art déco em Paris, no ano de 1925, apresentando-se como um conjunto de manifestações artísticas que teve como objetivo exteriorizar um espírito moderno por meio da arte decorativa. A autora relaciona a difusão pela associação aos avanços tecnológicos e pelas adaptações sofridas em cada país. No Brasil, o estilo atingiu todas as classes econômicas, sendo adotado de forma mais sistemática com produção extensa e única, por desenvolver materiais e técnicas próprias.

Nos estudos de Correia (2017) podemos constatar que no Brasil a arquitetura déco fez uso de princípios de hierarquização, expressos em formas escalonadas e enfatizando os acessos principais. Em casas populares a estética encontra-se na forma de detalhes ornamentais das fachadas, empregados cautelosamente, principalmente, nas platibandas.

Na cidade de Campina Grande, no século XX o estilo Art Decó fez parte da arquitetura. Melo (2020) atrela a gestão do prefeito Vergniaud Wanderley que implantou uma reforma urbanística pautada pelos discursos de progresso, modernidade, embelezamento e sanitaríssimo. Nesse contexto foram edificadas a Biblioteca Municipal, o Cine Teatro, a sede dos Correios, Telégrafo, assim como a Estação Nova com seu estilo Art Déco.

Os estudos de Queiroz (2010) reforçam essa relação do surgimento com a ruptura da implantação colonial e a introdução de toda uma tecnologia doméstica com intuito de modernizar e reformular o espaço público. A cidade possui um patrimônio art déco numeroso e significativo, erguido em áreas de expansão urbana ou substituindo uma considerável parcela dos antigos edifícios de herança colonial que predominavam na região central, conforme ilustrado na figura 01 . 


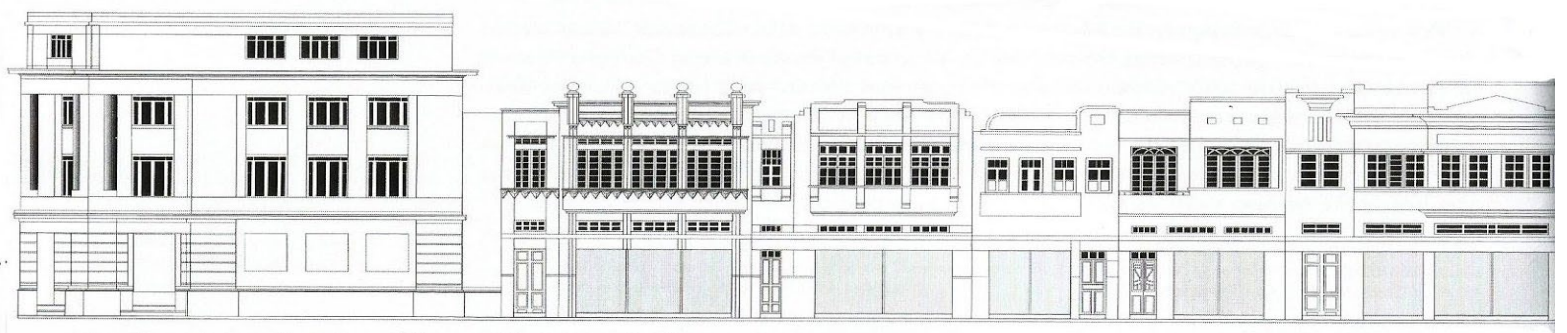

Figura 01 Rua Maciel Pinheiro/ lado ímpar/ $1^{\text {o }}$ quarteirão. Câmara municipal e sobrados comerciais - foto Rossi (2010)

Queiroz (2010) alerta sobre a importância da preservação dos nossos patrimônios, denuncia a descaracterização e a falta de sintonia existente entre o poder público com um dos poucos elos entre o século XXI e as memórias, modos de vida e o saber fazer da primeira metade do século XX.

\section{HISTÓRICO DA ESTAÇÃO NOVA}

Melo (2020) faz uma retrospectiva da chegada do trem, a partir do século XIX as cidades tornaramse símbolos da modernidade crescendo exponencialmente e sofrendo transformações culturais, sociais e demográficas. $\mathrm{O}$ trem nesse contexto serviu como um encurtador de distâncias, trazendo inovações e substituindo o animal lento pela máquina. Na cidade de Campina Grande o trem chegou em meados do século XX, carregando simbolismo, impulso econômico e comercial, transformando a cidade em um grande polo, com destaque no cenário nordestino. O primeiro ramal ligava Campina Grande à Itabaiana onde havia uma grande comercialização do algodão, daí a necessidade expansão de galpões e locais para armazenamento.

Ainda Melo (2020), relaciona a criação da Estação Nova, no ano de 1957, pela Rede Ferroviária Nacional, ao intuito de ampliar a estrutura ferroviária e atender às novas solicitações comerciais. O complexo ferroviário destinado a Estação Nova está localizado por meio da poligonal formada pela Av. Prof. Almeida Barreto, Av. Almirante Barroso e Av. Almirante Barroso, no Bairro Quarenta. O pátio é composto por 5 edifícios utilizados como depósitos, transporte de passageiros, oficina, posto de abastecimento, abrigo técnico e administrativo a figura 02 ilustra a disposição dos galpões no complexo ferroviário.

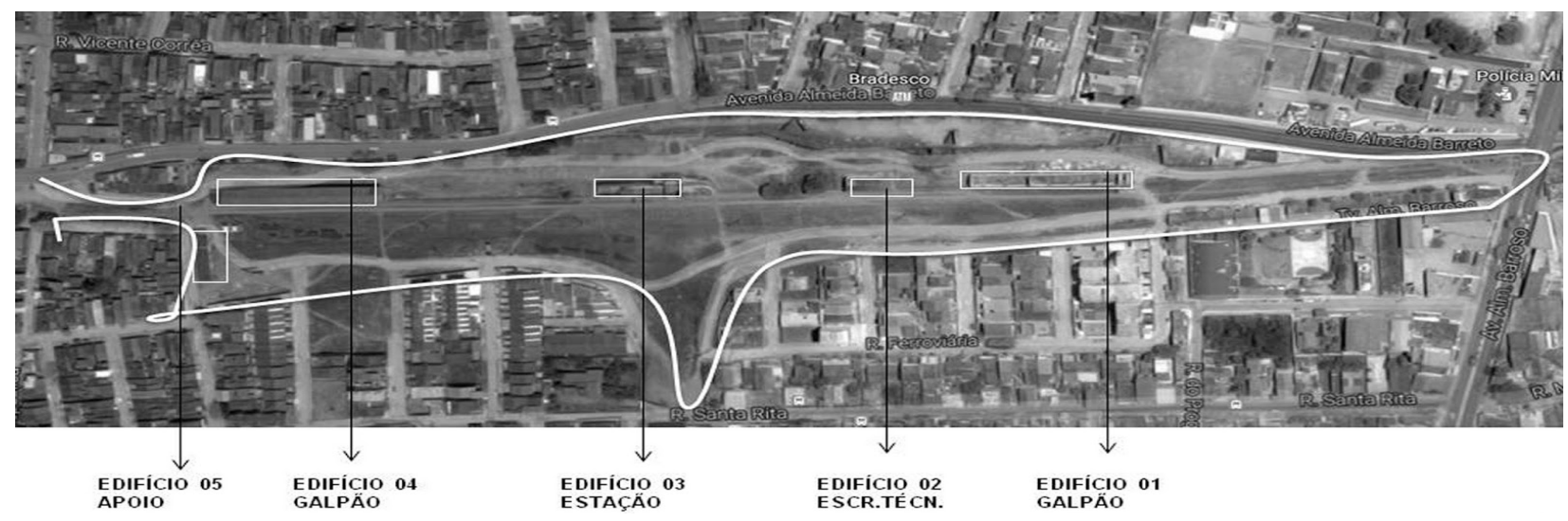

Figura 02 Complexo Ferroviário Estação Nova: Melo (2020) 
A edificação principal, objeto de análise deste estudo, foi inaugurada no dia 29 de janeiro de 1961, destinado a embarque e desembarque de passageiros, além de abrigar o sino da estação, relógio e o castelo do maquinista. Com o advento industrial automobilístico, o trem passou a ser visto como algo ultrapassado e a sociedade reformula-se e passa a ver nos transportes rodoviários as facilidades que os trens perderam. O transporte de passageiros foi extinto na década de 1980, e passaram a realizar apenas transporte de cargas.

Afonso (2017) descreve a composição da edificação pelas linhas arquitetônicas em estilo Art Déco, com volumetria limpa e sem ornamentos, com arremate por uma torre central, possui grades de esquadrias trabalhadas e um rico painel que tem como tema a vida na ferrovia, na figura 03 podemos identificar a volumetria da edificação.

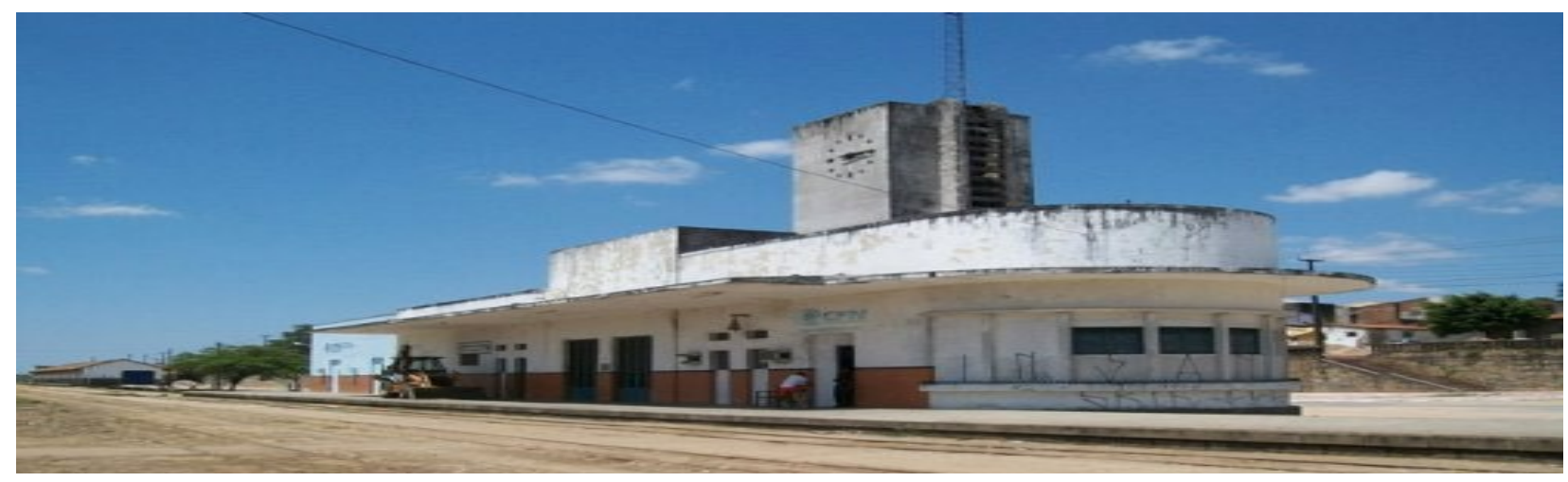

Figura 03 Estação de Campina Grande-nova em 12/2009. Foto Jonatas Rodrigues

Atualmente os imóveis encontram-se em estado de abandono pelo poder público. No que diz respeito a legislação vigente no art.8 da Lei $n^{\circ} 11483 / 2007$, cabe ao Departamento Nacional de Infraestrutura de Transportes - DNIT a responsabilidade pela conservação e manutenção dos bens imóveis no tocante a revitalização do setor ferroviário brasileiro. De acordo com o Ministério Público Federal, o município de Campina Grande demonstra interesse no uso e ocupação do conjunto ferroviário, e junto ao DNIT iniciou tratativas para realização de um Termo de Cessão.

\section{FACHADAS E MANIFESTAÇÕES PATOLÓGICAS}

Barth (2007), afirma que as fachadas têm o poder de produzir a imagem do edifício e de criar a sua identidade visual. Assim como elas podem, também, melhorar o desempenho ambiental e atuar como elemento condicionador natural da edificação.

Apesar de sua função estética e de durabilidade Borges et. al., (2014) as fachadas são os primeiros elementos a necessitar de intervenções, devido à maior exposição à agentes deterioração como ações climáticas, mecânicas e antropológicas.

De acordo com Pereira (2012) o termo patologia nas edificações vem sendo utilizado em analogia com as enfermidades da medicina. Ela consiste no estudo de danos sistemáticos dos acidentes e suas causas. $\mathrm{O}$ autor reforça que os principais problemas em edificações, são evolutivos que tendem a se agravar com o tempo, porém pode-se compreender a natureza, a origem e os mecanismos envolvidos.

Feigelson e Couri (2011) alertam que os imóveis históricos possuem características construtivas peculiares e devem ser analisados de forma distinta de uma edificação comum, necessitando de um estudo adequado de revitalização e restauro. Os autores reforçam a preocupação com a durabilidade 
das edificações pois elas possuíam um sistema construtivo simples e com materiais e técnicas que já estão em desuso.

\section{MAPEAMENTO DE DANOS}

Macedo apud Tinoco (2009) salienta que o método com maior eficiência e de simples aplicação na detecção, levantamento e representação de danos ou manifestação patológicas é a elaboração do Mapa de Danos e o mapeamento de danos. Justifica-se esse procedimento porque, através desse método, é possível caracterizar os níveis de degradação da edificação através da representação gráfica e fotográfica dela, tornando possível o conhecimento sobre as alterações estruturais e funcionais.

Para melhor entendimento deste trabalho, é importante salientar a diferença entre Mapa de Danos e Mapeamento de Danos. Tinoco (2009) diferencia o primeiro como um documento ou conjuntos de documentos gráficos e fotográficos que ilustram as realidades de uma edificação numa determinada data ou tempo; o segundo se refere aos processos de investigações, levantamentos e produção dos dados para elaboração do mapa.

Correa e Tirello (2012) afirmam que no caso das edificações históricas, se feito criteriosamente, resulta em um importante documento ilustrador, na medida em que pode agrupar informações relativas à quantidade, qualidade e intensidade das avarias dos materiais e estruturas dessas construções, constituindo-se em uma legítima e importante instância de diagnósticos dos bens culturais.

Não existe um modelo normativo a ser seguido, todavia neste estudo utilizaremos uma adaptação do modelo de representação gráfica proposto por Achiamé e Hautequestt Filho (2018), representado na figura 04. Composto de hachuras sólidas e coloridas com legenda e fotografias identificando os principais danos na edificação. Os autores agruparam em uma única ficha de classificação de danos, 24 manifestações patológicas mais recorrentes em edificações brasileiras.
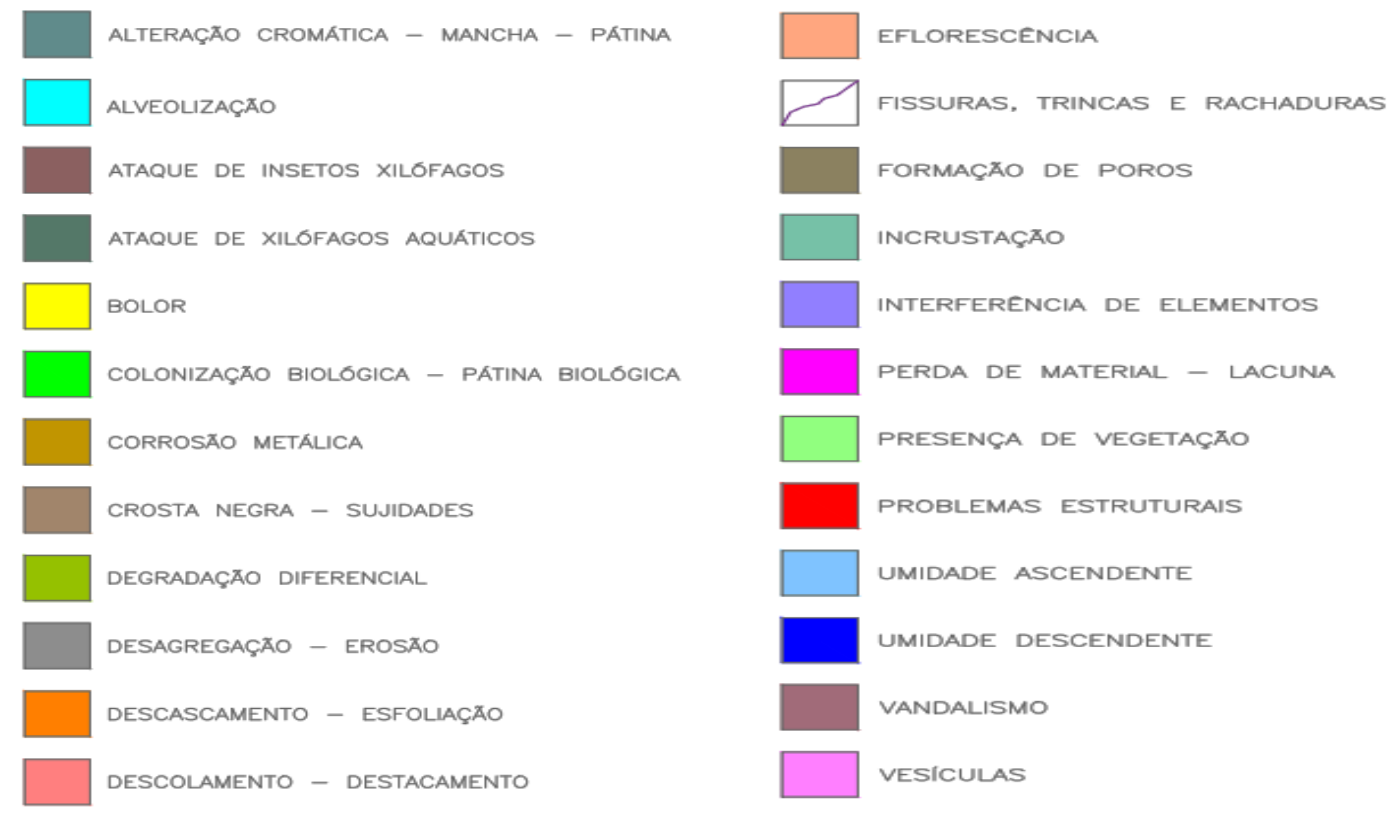

Figura 04 Simbologia adaptada Fonte: Achiamé e Hautequestt Filho (2018) 
Todo o mapeamento foi desenvolvido pelo método indireto, conforme descreve Tinoco (2009), ele consiste na interpretação de elementos escritos e gráficos, com ações não destrutivas prezando pela premissa que o conhecimento deve ser construído.

\section{MATRIZ DE GRAVIDADE, URGÊNCIA E TENDÊNCIA (GUT)}

O método da Matriz GUT (Gravidade, Urgência, Tendência) consiste na priorização nas intervenções de manutenção e reabilitação dos danos e/ou anomalias, sendo uma ferramenta importante para auxiliar na tomada de decisões dos gestores públicos. Braga (2019) explica que para esta avaliação, o método dispõe do uso de números que são associados a cada dano inspecionado, a fim de definir os graus de criticidade em relação a cada problema encontrado.

Para classificação GUT sobre as gravidades, foram extraídos quadros do estudo de Braga (2019) ilustradas nos quadros abaixo, onde a Gravidade (G) trata-se da importância do problema e seu potencial de dano (quadro 1). A Urgência (U) estar associado ao prazo para a realização das intervenções (quadro 02), e a Tendência (T) refere-se à evolução do problema em função do tempo (quadro 03).

\begin{tabular}{|c|c|c|}
\hline Grau & Definição do Grau & Nota \\
\hline TOTAL & $\begin{array}{l}\text { Risco de morte, impacto irrecuperável com perda excessiva de } \\
\text { desempenho, Prejuízo financeiro muito alto. }\end{array}$ & 10 \\
\hline ALTA & $\begin{array}{l}\text { Perigo de lesão aos usuários, danos recuperáveis ao meio ambiente } \\
\text { e a edificação }\end{array}$ & 8 \\
\hline MÉDIA & $\begin{array}{l}\text { Risco à saúde dos usuários ocasionados pela degradação de } \\
\text { sistemas, avarias ao meio ambiente reversíveis, perda financeira } \\
\text { média. }\end{array}$ & 6 \\
\hline BAIXA & $\begin{array}{l}\text { Sem risco de saúde aos usuários, baixa degradação ao meio } \\
\text { ambiente, necessidade de substituição de alguns sistemas, perda } \\
\text { financeira baixa. }\end{array}$ & 3 \\
\hline NENHUMA & $\begin{array}{c}\text { Sem risco de saúde ou plenitude física, mínima deterioração do } \\
\text { ambiente, nenhum dano de valor. }\end{array}$ & 1 \\
\hline
\end{tabular}

Quadro 01 Classificação GUT sobre as Gravidades, Braga (2019)

\begin{tabular}{|c|c|c|}
\hline Grau & Definição do Grau & Nota \\
\hline TOTAL & $\begin{array}{c}\text { Acontecimento imediato, necessidade de interdição do imóvel sem } \\
\text { prazos extras. }\end{array}$ & 10 \\
\hline ALTA & Acontecimento na iminência de acontecer, urgente intervenção. & 8 \\
\hline MÉDIA & $\begin{array}{l}\text { Adversidade prevista para breve, necessidade de intervir } \\
\text { rapidamente. }\end{array}$ & 6 \\
\hline BAIXA & $\begin{array}{l}\text { Inicialização de um incidente, intervenção ainda em forma de } \\
\text { planos. }\end{array}$ & 3 \\
\hline NENHUMA & $\begin{array}{c}\text { Adversidade imprevista, mas necessário acompanhamento para } \\
\text { futuras manutenções. }\end{array}$ & 1 \\
\hline
\end{tabular}

Quadro 2 Classificação GUT sobre as Urgências, Braga (2019) 


\begin{tabular}{|c|c|c|}
\hline Grau & Definição do Grau & Nota \\
\hline TOTAL & Progresso da manifestação imediato, podendo haver pioras a \\
qualquer instante. & 10 \\
\hline ALTA & Evolução da situação prestes a ocorrer & 8 \\
\hline MÉDIA & Evolução a médio prazo. & 6 \\
\hline BAIXA & $\begin{array}{c}\text { Possível evolução a longo prazo. Poderá vir a ocorrer. Situação de } \\
\text { demora. }\end{array}$ & 3 \\
\hline NENHUMA & Situação estabilizada, sem evolução do caso. & 1 \\
\hline
\end{tabular}

Quadro 3 Classificação GUT sobre Tendências, Braga (2019)

Para obter as prioridades, classificam-se os problemas de acordo com o produto dos valores (GxUxT) atribuídos para as manifestações patológicas de cada edificação.

\section{RESULTADOS}

A seguir serão ilustradas as principais manifestações patológicas identificadas nas fachadas da edificação principal destinada à Estação Ferroviária Nova de Campina Grande/PB. Elas podem se apresentar como resultado de combinações de causas que vão de problemas com qualidade dos materiais aplicados à agentes externos como à presença de umidade, variações de temperatura etc. O levantamento fotográfico das fachadas revela suas disposições para melhor identificação no mapeamento de danos. As figuras 5, 6, 7 e 8 são de acervo próprio retiradas da câmera de celular.

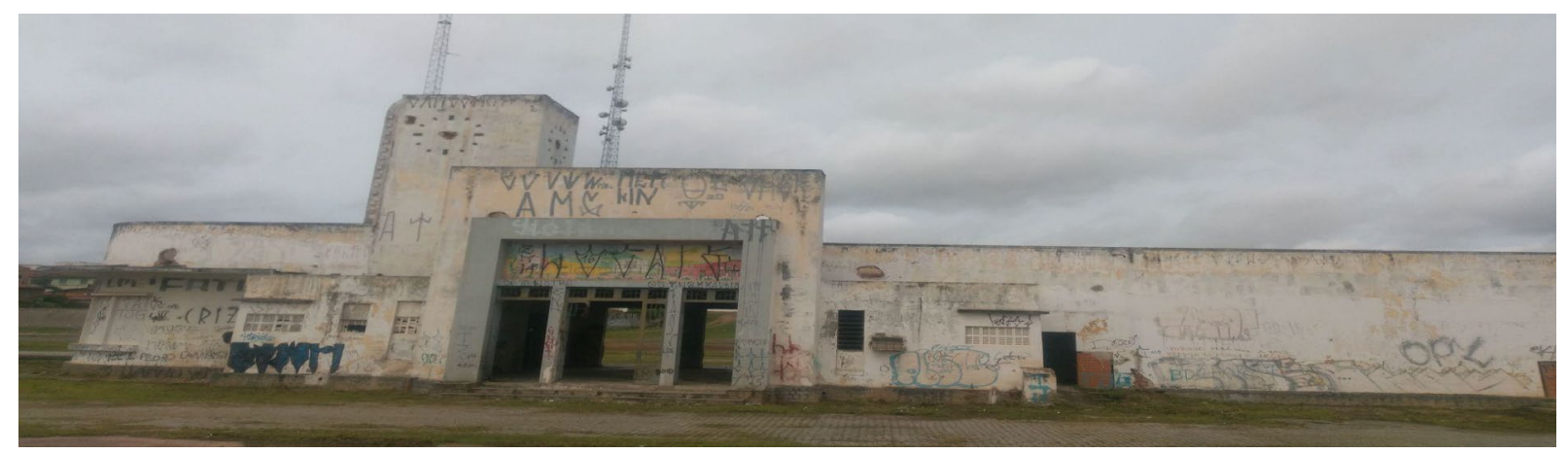

Figura 05 Fachada principal estação nova Fonte: acervo próprio (2021)

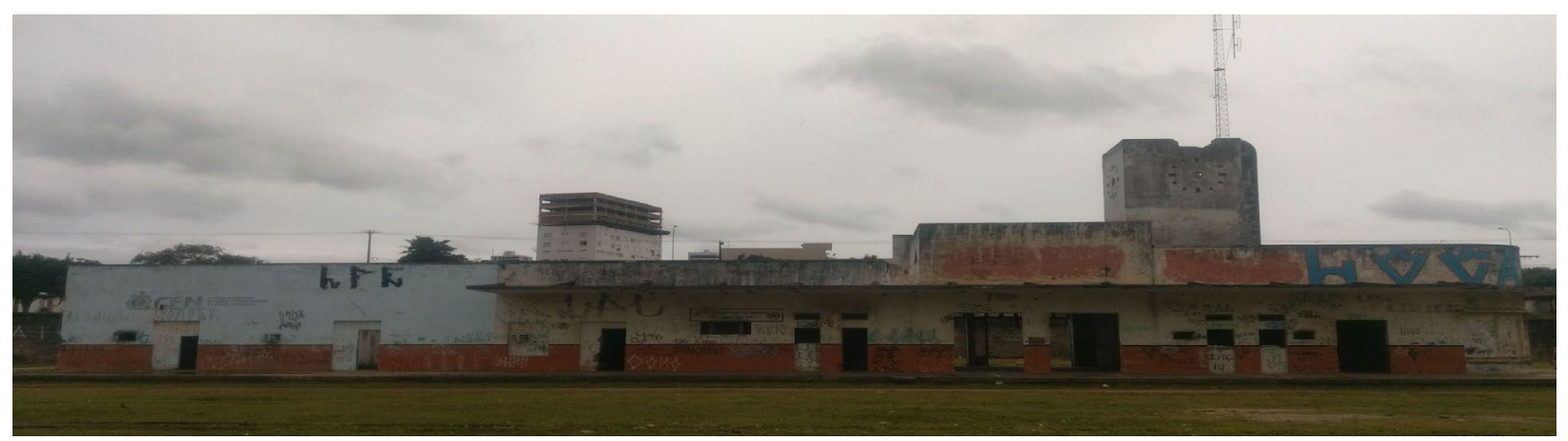

Figura 06 Fachada destinada a embarque e desembarque de passageiros e mercadorias Fonte: acervo próprio (2021) 


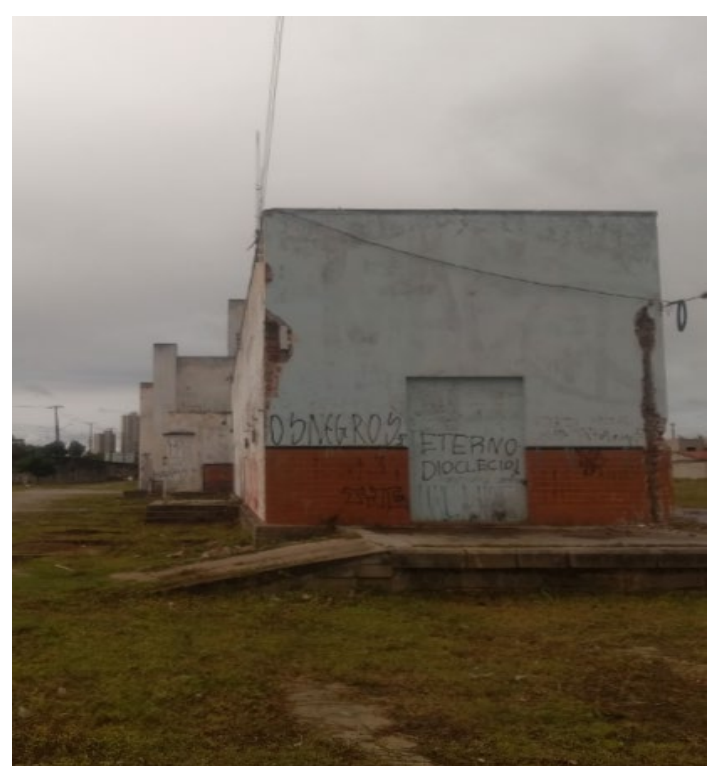

Figura 07 Fachada leste Fonte: acervo próprio (2021)

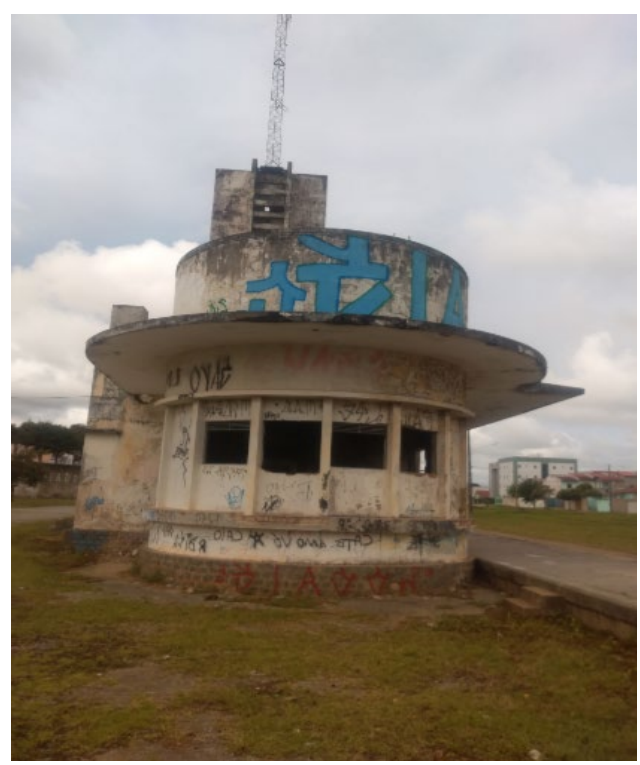

Figura 08 Fachada oeste Fonte: acervo próprio (2021)

Utilizando a adaptação da proposta de Achiamé e Hautequestt (2018) padronizamos e obtivemos os mapas de danos das fachadas, representando graficamente as principais manifestações patológicas presentes.

$\mathrm{Na}$ fachada principal, figura 09 as principais manifestações patológicas identificadas foram: vandalismo, sujidades, problemas estruturais, corrosão metálica, lacunas por perda de material (esquadrias), descolamento, fissuras mapeadas. 


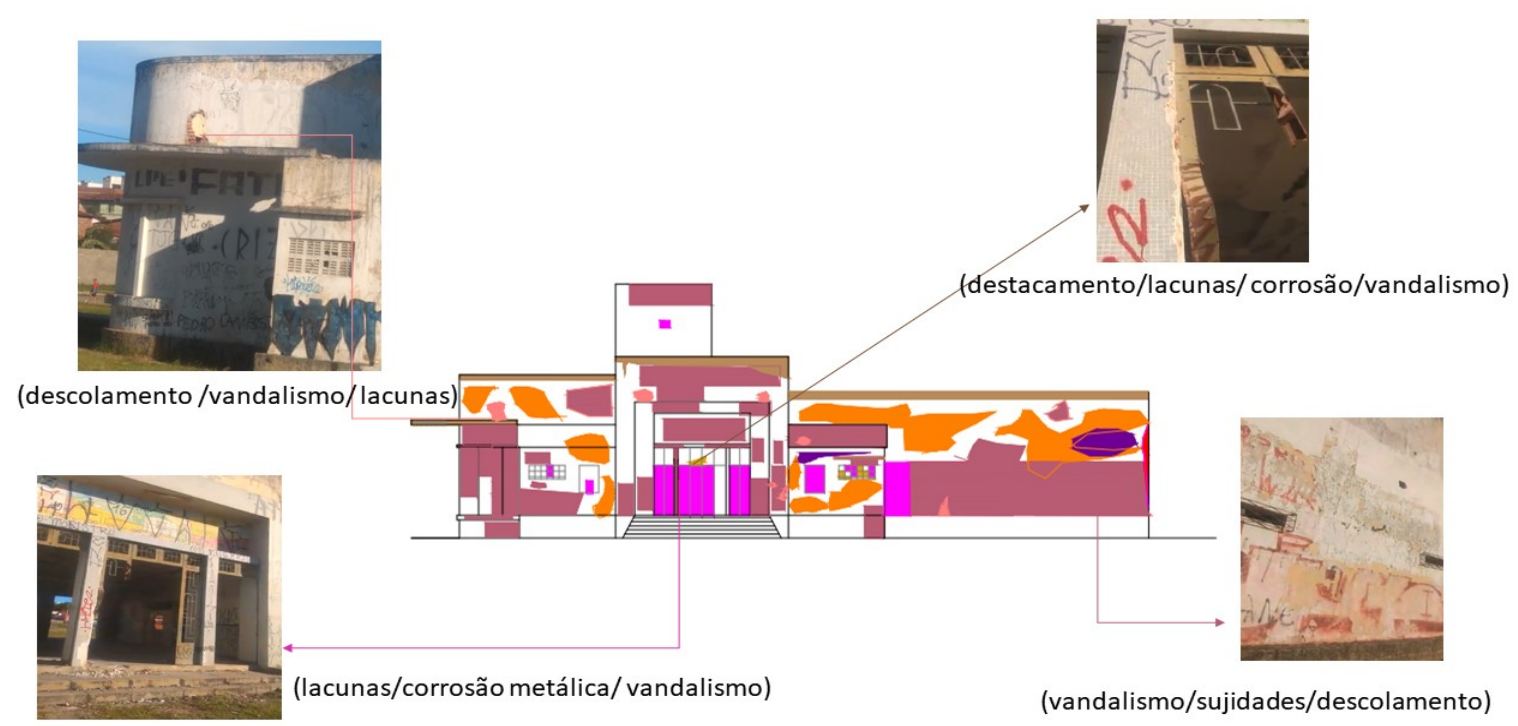

A fachada projetada para embarque e desembarque de passageiros e mercadorias, figura 10, foram encontradas manifestações: vandalismo, lacunas por perda de material, sujidades, fissuras mapeadas, bolor e descolamento.

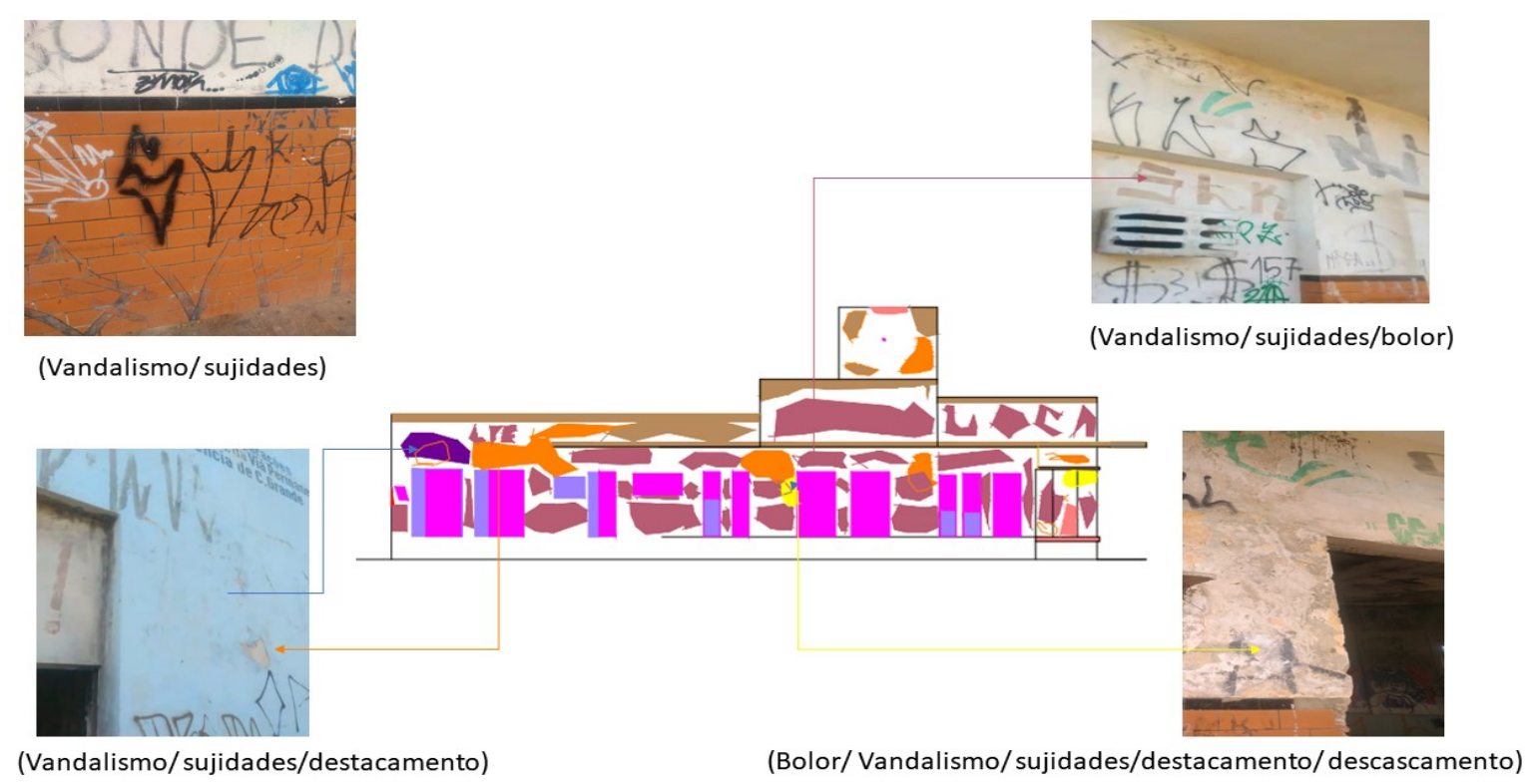

A fachada leste, figura 11, apresentou sujidades, vandalismo, fissuras mapeadas, problemas estruturais (amarração danificada), descolamento. 


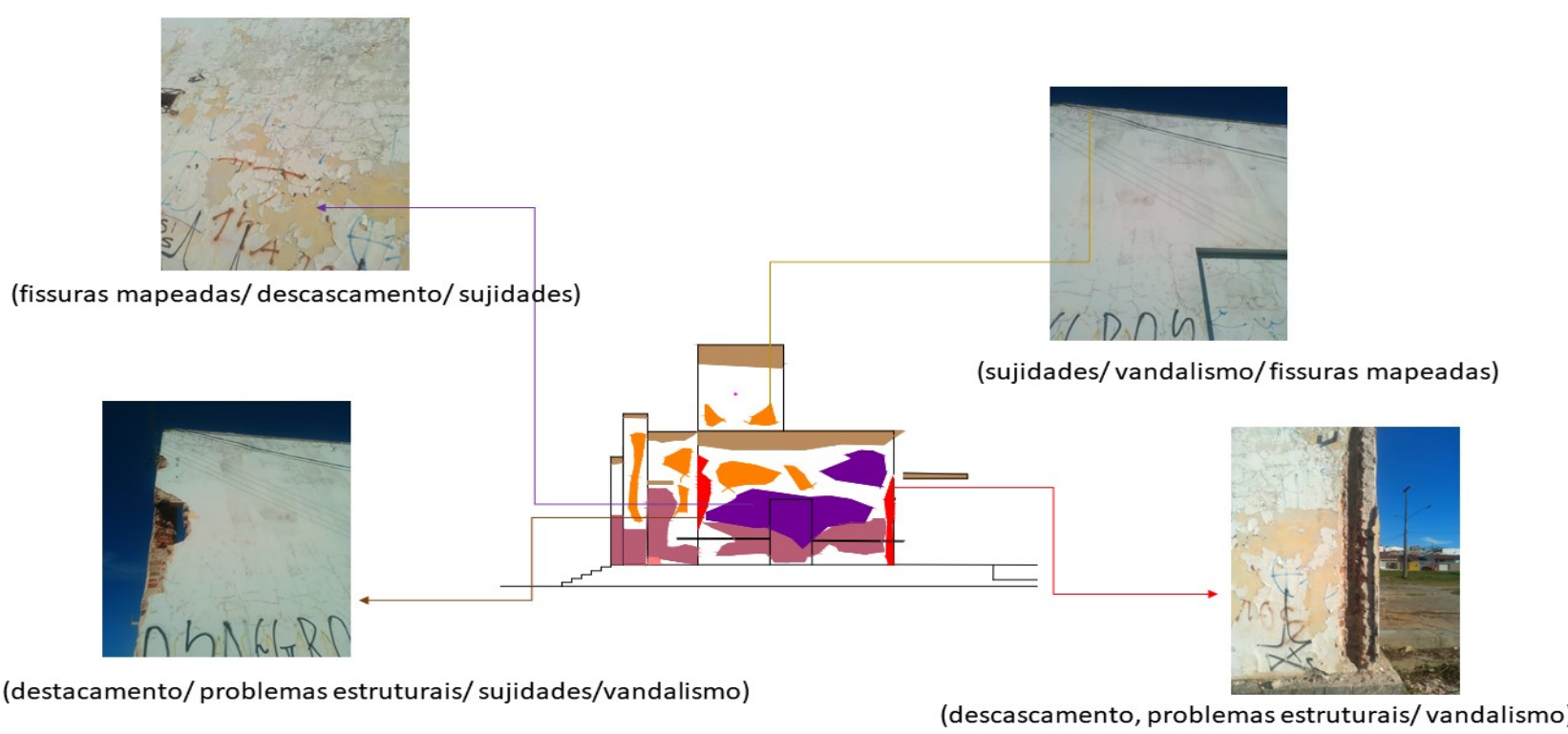

Enquanto na fachada oeste, figura 12, foram identificadas as manifestações patológicas: Sujidades, vandalismo, bolor, descolamento, descascamento e presença de lacunas por perda de materiais (esquadrias).

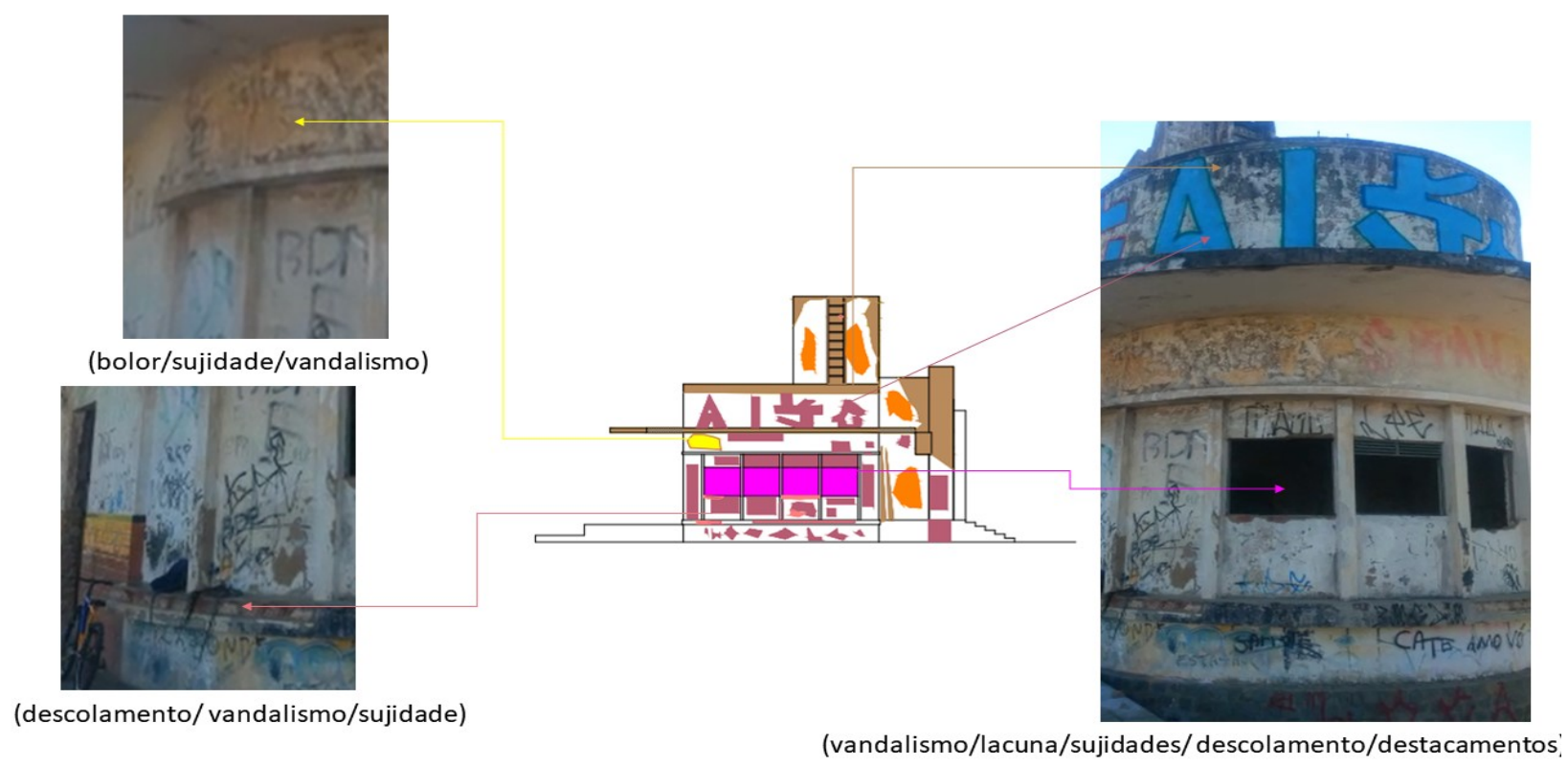

A metodologia GUT é uma ferramenta de controle que é utilizada preferencialmente para estabelecer prioridades e indicar por onde se deve começar. Após a inspeção das fachadas da edificação e o seu posterior mapeamento, atribuímos pontos de acordo com as manifestações patológicas identificadas nas fachadas, a seguir o formulário de Gravidade, Urgência e tendência aplicado, conforme detalhado na Tabela 1. 
Tabela 1. Formulário de Gravidade, Urgência e Tendência

\begin{tabular}{|c|c|c|c|c|}
\hline $\begin{array}{c}\text { Manifestações } \\
\text { Patológicas }\end{array}$ & $\begin{array}{c}\text { Gravidade } \\
(\mathbf{G})\end{array}$ & $\begin{array}{c}\text { Urgência } \\
(\mathbf{U})\end{array}$ & $\begin{array}{c}\text { Tendência } \\
\text { (T) }\end{array}$ & G.U.T \\
\hline Problemas estruturais & 8 & 8 & 8 & 512 \\
\hline Vandalismo & 6 & 6 & 10 & 360 \\
\hline Descolamento & 8 & 6 & 3 & 144 \\
\hline Fissuras mapeadas & 6 & 6 & 1 & 36 \\
\hline Perda de Materiais & 10 & 3 & 1 & 30 \\
\hline Descascamento & 6 & 1 & 3 & 18 \\
\hline
\end{tabular}

As manifestações patológicas que mais incidiram sobre as fachadas foram elencadas no formulário em ordem decrescente de prioridade e expostas na figura 13. Elas associadas tendem a se potencializar com o decorrer do tempo. Os problemas estruturais estão diretamente relacionados às ações antropológicas, é necessário refazer as amarrações das alvenarias das áreas atingidas, para garantir o desempenho da edificação. Antes de qualquer intervenção nas fachadas é necessário a investigação e o tratamento da origem das manifestações patológicas.

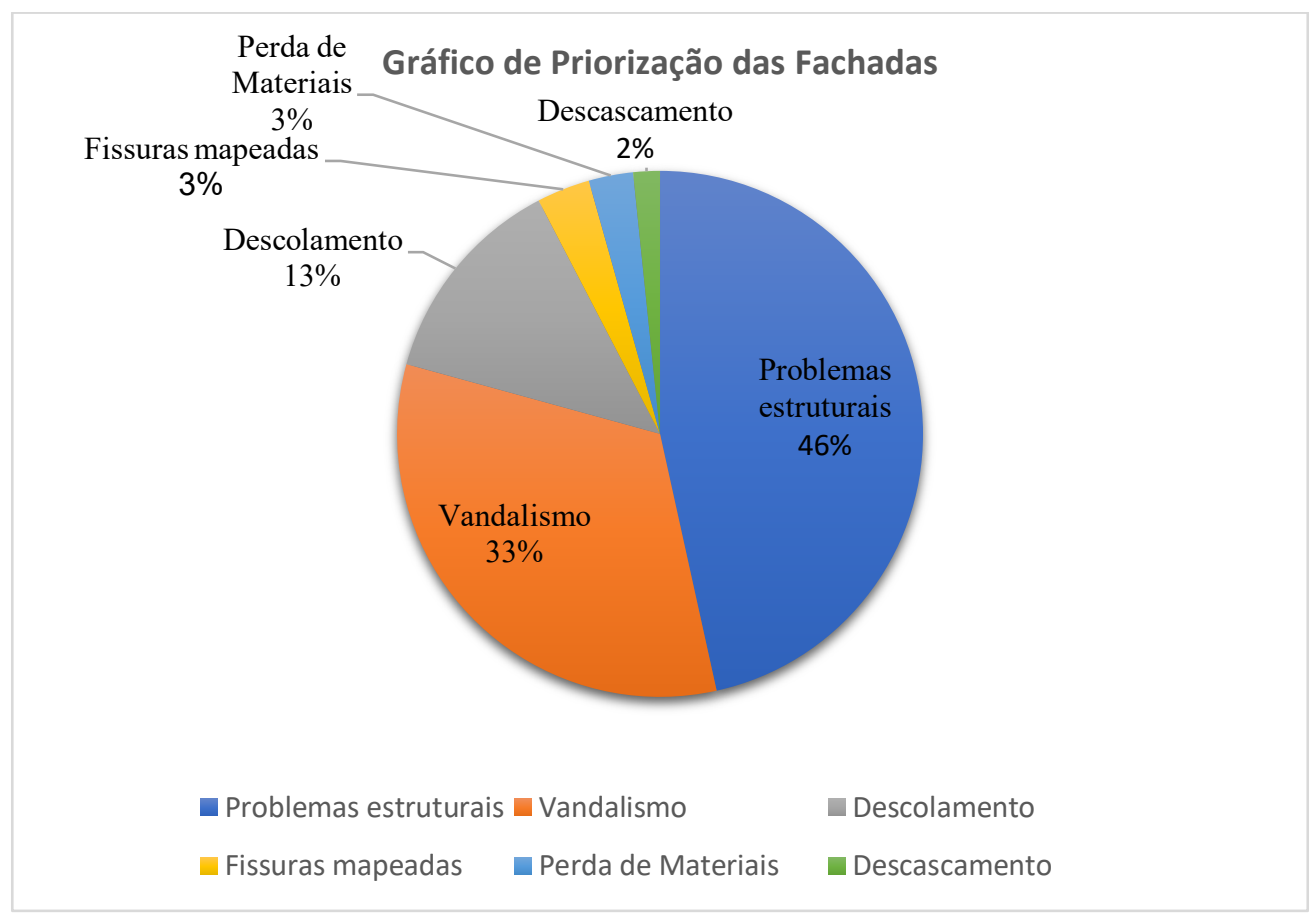

Figura 13 Priorização das fachadas

As fissuras mapeadas apresentaram-se em todas as fachadas da edificação, possuem formas variadas e distribuídas pela superfície do revestimento argamassado, elas podem ser causadas por espessuras de camadas de revestimento exageradas, aplicação em condições desfavoráveis, processo de cura desrespeitado.

Descolamentos são causados pela perda de aderência, podendo se apresentar em placas, com pulverulência e com empolamento. É constantemente identificado o descascamento da pintura e o vandalismo que produz estragos, destruição dos bens sejam públicos com o propósito de arruinálos. 


\section{CONCLUSÕES}

As manifestações patológicas em fachadas de edifícios são comuns, por estarem mais expostas à ação de intempéries, deste modo, mais sujeitas a degradações. É importante investigar cuidadosamente estas manifestações, pois uma eventual falha no diagnóstico, ocasiona ações ineficientes. Outro ponto de extrema importância é a ausência de monitoramento e de um sistema de manutenção sistematizado, essas ferramentas evitariam que os danos fossem agravados e reduziriam a necessidade de reformas, reparos ou até mesmo reconstituição desses equipamentos. O mapeamento de danos mostrou-se um instrumento eficaz para auxiliar profissionais e projetistas no planejamento e na tomada de decisões a serem executadas. De posse do mapa de danos das fachadas, elaborado após análise da estação ferroviária nova, foi possível identificar os danos acometidos pela edificação. A metodologia GUT é uma ferramenta muito útil para priorizar intervenções e pode dar suporte para manutenção de edificações contribuindo para conservação e segurança.

As fachadas em sua maioria apresentam um elevado índice de alterações de danos atrelados diretamente à origem antropológica ou a ausência delas. As principais manifestações patológicas atuantes dizem respeito a fissuras, problemas estruturais, descascamentos, descolamentos de argamassa e danos relacionados à umidade.

Este importante monumento em art Déco, referência da modernização e da cultura algodoeira da cidade, encontra-se abandonado. Seu estado de conservação é preocupante, necessitando de intervenções imediatas e de soluções que possibilitem segurança, durabilidade e evitem que os danos sejam ainda mais potencializados.

A sociedade corre o risco de perder um dos exemplares mais significativos em art Déco, que representa o patrimônio cultural e industrial da cidade. Fica como sugestão para trabalhos futuros, a aplicação da metodologia para inspecionar o equipamento como um todo analisando estado da cobertura e dos demais cômodos. É necessário requalificar estação, ocupa-la. Espera-se que as informações obtidas nesta pesquisa venham a complementar outros estudos para perpetuar a memória urbana, cultural do município.

\section{AGRADECIMENTOS}

A Unifacisa, pelo apoio no desenvolvimento deste trabalho.

\section{REFERENCIAS}

ACHIAMÉ, G. G.; HAUTEQUESTT FILHO, G. C. Diretrizes para representação gráfica de mapa de danos. Vitória: PATORREB, 2018. http://www.nppg.org.br/patorreb/files/artigos/80626.pdf Acesso em: 4 jun. 2021.

AFONSO, Alcilia. Pelas linhas do trem. Pelas linhas do tempo. O pátio ferroviário da Estação nova de Campina Grande. Anais do IV Seminário Internacional da Academia de Escolas de Arquitetura e Urbanismo de Língua Portuguesa. Belo Horizonte: 2017

ANDRADE, Inês El-Jaick ; RIBEIRO, Rosina Trevisan ; PIMENTEL, Viviane ; COELHO, Carla ; MELO, Carina . Olhares sobre o patrimônio edificado: o conceito de valor. In: XXIII Simpósio Nacional de História/ANPUH, 2005, Londrina. XXIII Simpósio Nacional de História: História Guerra e Paz. Londrina: Universidade Estadual de Londrina/UEL; Associação Nacional de História/ANPUH, 2005. v. 1. p. 462-462. 
BARTH. Fernando;VEFAGO. Luiz H. Maccarini. Tecnologia de Fachadas Pré-Fabricadas. Florianópolis: Editora Letras Contemporâneas, 2007

BARTHEL, C.; LINS, M.; PESTANA, F. O papel do mapa de danos na conservação do patrimônio arquitetônico, Recife: FUNDARPE, s/d. 2009. Disponível em: https://core.ac.uk/download/pdf/153566136.pdf Acesso em: 4 jun. 2021.

BORGES, E. A. M. ; CARASEK, Helena ; CASCUDO, O. . . REEC - Revista Eletrônica de Engenharia Civil , v. 8, p. 20-37, 2014.

Braga, I. C., Brandão, F. S., Ribeiro, F. R. C., Diógenes, A. G. (2019), “Aplicação da Matriz GUT na análise de manifestações patológicas em construções históricas”, Revista ALCONPAT, 9(3), pp. 320 - 335, DOI: http://dx.doi.org/10.21041/ra.v9i3.400

CORREA, R. H.; TIRELLO, R. A. Sistema normativo para mapa de danos de edifícios históricos aplicado à Lidgerwood manufacturing company de Campinas. Campinas, s/d. Acesso em: 4 jun. 2021.

CORREIA, T. de B. O art déco na arquitetura brasileira. Revista UFG, [S. 1.], v. 12, n. 8, 2017. Disponível em: https://www.revistas.ufg.br/revistaufg/article/view/48295. Acesso em: 4 jun. 2021. Feigelson, S ; Couri, Gilberto Adib . Pericias em bens históricos, patologias, recuperação e avaliação. 2011.

MACEDO, Aureliano Amaro Ribeiro Souza de. Mapa de danos das fachadas do Teatro de Santa Isabel, Recife - Pernambuco. 2016. 83 f. Dissertação (Mestrado) - Universidade Católica de Pernambuco. Pró-reitoria Acadêmica. Coordenação Geral de Pós-graduação. Mestrado em Engenharia Civil, 2016.

MELO, A.A. (2020).Os pátios ferroviários de Campina Grande: Pelas linhas do trem, pelas linhas do tempo. Disponível em: https://memoriaferroviaria.rosana.unesp.br/ocs/index.php/C_IHF/VIICIHF/paper/view/111.

Acesso em: 4 jun. 2021.

Munduruca, Elianne Auxiliadora Moreira Borges. Reabilitação em Edifícios e Monumentos Art Déco - Métodos de Avaliação dos Revestimentos de Fachadas [manuscrito] / Elianne Auxiliadora Moreira Borges Munduruca. - 2013.

PEREIRA, Luciana Manzoni. Avaliação das Patologias e da Biodeterioração na Biblioteca Central da UFSM. Dissertação (Mestrado em Engenharia Civil e Ambiental) Universidade Federal de Santa Maria, R.S., 2012.

QUEIROZ, Marcus Vinicius Dantas de . Art Déco em Campina Grande (PB): valorização, patrimonialização e esquecimento. REVISTA UFG (IMPRESSO) , v. 8, p. 35-40, 2010.

ROSSI, L. M. Art Déco Sertanejo e uma revitalização possível: programa Campina Grande Déco. Revista UFG, [S. l.], v. 12, n. 8, 2017. Disponível em: https://www.revistas.ufg.br/revistaufg/article/view/48297. Acesso em: 4 jun. 2021.

SANTOS, Danilo Gonçalves dos. Estudo da vida útil e degradação de fachadas em argamassa a partir da inspeção de edifícios. 2018. xv, 122 f., il. Dissertação (Mestrado em Estruturas e Construção Civil)_-Universidade de Brasília, Brasília, 2018.

SANTOS, J.K.O. Memórias dos trilhos [manuscrito]: Construção e vivências da Estação Ferroviária Nova de Campina Grande - PB (1957-1998)/ Jessica Kaline Oliveira Santos - 201972 p. Trabalho de conclusão de Curso (graduação em História) UEPB, Centro de Educação, 2019.

SCHEIDEGGER, Guilherme Marchiori, CALENZANI, Carla Lorencini. Patologia, recuperação e reparo das estruturas de concreto. Revista Científica Multidisciplinar Núcleo do Conhecimento. Ano 04, Ed. 03, Vol. 05, pp. 68-92. Março de 2019. ISSN: 2448-0959.

TINOCO, J. E. L. MAPA DE DANOS RECOMENDAÇÕES BÁSICAS. Centro de Estudos Avançados da Conservação Integrada. Textos para Discussão - Série 2: Gestão de Restauro. Olinda, 2009. 